\title{
Application of tumor-node-metastasis staging 2002 version in locally advanced hepatocellular carcinoma: is it predictive of surgical outcome?
}

\author{
Binkui Li ${ }^{1,2}$, Yunfei Yuan ${ }^{1,2^{*}}$, Guihua Chen ${ }^{3}$, Liru He ${ }^{1,4}$, Yaqi Zhang ${ }^{1,2}$, Jinqing Li ${ }^{1,2}$, Guohui Li ${ }^{1,2}$, Wan Yee Lau ${ }^{5}$
}

\begin{abstract}
Background: Locally advanced (pT3-4NOMO) hepatocellular carcinoma (HCC) is a heterogeneous group of tumors, which consists of four different categories, including HCC with "multiple tumors more than $5 \mathrm{~cm}$ ", "major vascular invasion", "invasion of adjacent organs", and "perforation of visceral peritoneum". The aim of our study was to verify whether the 2002 version of the Tumor-Node-Metastasis staging system could predict surgical outcomes in patients with locally advanced HCC.

Methods: We retrospectively reviewed 298 patients with pT3-4NOMO HCC who underwent hepatic resection from 1993 to 2000 in an academic tertiary hospital. Overall survival (OS) and cumulative recurrence rate (CRR) of the four categories of locally advanced HCC patients were compared.

Results: In multivariate analysis, major vascular invasion was identified as the most significant factor (HR $=3.291$, $95 \% \mathrm{Cl} 2.362-4.584, P<0.001)$ followed by cirrhosis status on OS, and was found to be the only independent factor of CRR ( $\mathrm{HR}=2.242,95 \% \mathrm{Cl} 1.811-3.358, P<0.001)$ in patients with locally advanced HCC. Among the four categories of locally advanced HCC, OS was significantly worse, and CRR was significantly higher in patients with HCC with major vascular invasion (pT3) than with multiple tumors more than $5 \mathrm{~cm}$ (pT3); or tumor invasion of adjacent organs (pT4); or perforation of visceral peritoneum (pT4). No significant differences were observed in OS or CRR between the latter three groups of patients.

Conclusions: HCC with major vascular invasion, which are classified as pT3 under the current TNM staging, have the worst prognosis when compared with the other categories of pT3-4 disease. There is a need to redefine the T classification and to stratify locally advanced HCC.
\end{abstract}

\section{Background}

Hepatocellular carcinoma ( $\mathrm{HCC}$ ) is one of the most common malignant tumors in the world with a globally increasing annual incidence [1,2]. For accurate prognostic assessment after partial hepatectomy and patient selection for adjuvant therapy, the pathologic tumornode-metastasis (pTNM) staging system has traditionally been used. This TNM staging system has the advantages of a more detailed $\mathrm{T}$ classification than in any other staging systems [3]. However, the current 2002 TNM staging system is not completely satisfactory. The

\footnotetext{
* Correspondence: yuanyf@mail.sysu.edu.cn

${ }^{1}$ State Key Laboratory of Oncology in South China, Guangzhou, China

Full list of author information is available at the end of the article
}

stratification and the prognostic classification of advanced $\mathrm{T}$ stages of HCC are most debatable [4-7].

In the 2002 version of the TNM staging system, locally advanced HCC consists of four categories of diseases, with pT3 being classified as multiple tumors more than $5 \mathrm{~cm}$; or tumors with tumor thrombus within the major branch of portal or hepatic veins, and pT4 being classified as tumors with direct invasion of adjacent organs other than gallbladder; or perforation of visceral peritoneum [8,9]. Although major vascular invasion has been recognized as a very strong predictive factor of dismal prognosis, [6,7] and several studies have also shown invasion of adjacent organs or perforation of visceral peritoneum was not definitely associated with a worse survival, $[10,11]$ HCC with invasion of adjacent organs or perforation of visceral peritoneum but not major 
vascular invasion are classified as pT4 in the current 2002 TNM staging system. These published data strongly suggest $\mathrm{HCC}$ in advanced $\mathrm{T}$ stages are not classified appropriately under the current TNM classification.

In this study, we retrospectively analyzed the prospectively collected data of 298 patients with pT3-4NOM0 HCC who underwent partial hepatectomy to analyze the ability of the current TNM staging system to predict survival. Overall survival (OS) and cumulative recurrence rate $(C R R)$ of the four categories of locally advanced HCC patients were also compared.

\section{Methods}

\section{Patients}

Between January 1993 and December 2000, 890 patients underwent hepatic resection for HCC with curative intent, which was defined as macroscopically complete tumor resection at Sun Yat-sen University Cancer Center. Three hundred and five (34.3\%) patients were classified as locally advanced stages (pT3-4N0M0) according to the 2002 version of American Joint Committee on Cancer (AJCC)/International Union Against Cancer (UICC) TNM staging system $[8,9]$. Seven patients who died within 30 days of operation were excluded, leaving 298 patients for the analyses.

Preoperative liver functional reserve was assessed by blood biochemistry, Child-Pugh grading, and indocyanine green retention rate at 15 minutes (ICGR15). Only ChildPugh A patients were offered major hepatic resection, which was defined as the resection of three or more Couinaud's liver segments. In selected Child-Pugh B patients, minor hepatectomy, defined as resection of two or fewer liver segments, was carried out. MELD score was also calculated using pre-operative values of three laboratory tests: INR for prothrombin time, serum total bilirubin and serum creatinine [12]. In our daily practice, the "surgical margin" examination procedure is as follows: the marginal liver tissues taken from the "tumor bed" in the residual liver were used for pathologic review to examine whether it is tumor-free. Both parenchymal involvement of the margin and vascular permeation at the margin were considered as "microscopic positive margin" (which means R1 resection). In the present study, all the tumors had been macroscopically completely resected with a microscopically tumor-free margin proven by the pathologists (which means R0 resection). We define those with an obvious margin as "margin $>0$ $\mathrm{mm}$ ", and the others whose tumor was resected along with the edge of the tumor without an obvious margin but microscopically also with a tumor-free margin as "margin $=0 \mathrm{~mm}$ ". Tumors with involvement of the ipsilateral branch of the portal or hepatic veins or invasion of adjacent organs were considered resectable provided that en-bloc resection of the entire tumor could be performed with a tumor-free margin. Multiple tumors in more than one hemilivers were resected using extended right or left hepatectomy in patients with adequate hepatic functional reserve (Child-Pugh A and ICGR15 $\leq 10 \%$ ); otherwise, separate minor hepatectomy of the tumors in the 2 hemilivers were performed.

Histological diagnosis of HCC was reconfirmed by review of pathologic slides. Tumor grade was assessed using the nuclear grading scheme as outlined by Edmondson and Steiner. Tumor size was based on the largest diameter of the tumor in the resected specimen. The number of HCCs was defined by the total number of nodules, including intrahepatic metastasis. Major vascular invasion was defined as gross invasion of the trunk or the main branches of the portal or hepatic veins. Invasion of adjacent organs was defined as gross invasion of an adjacent organ other than the gallbladder which was resected en-bloc with the liver tumor. Perforation into visceral peritoneum was based on gross and histological study of the visceral peritoneum.

This study is a retrospective study of a prospectively collected database. All clinicopathological data were collected at the patient's presentation and at follow-up visits until the patient died or lost to follow-up. We regularly updated the database especially for tumor recurrence and survival status. This study was approved by the Clinical Research Ethics Committee of Sun Yatsen University Cancer Center and conformed to the ethical guidelines of the 1975 Declaration of Helsinki and the current ethical guidelines. Written informed consent for examination and treatment was obtained from each patient.

\section{Follow-up}

This study was censored on June 30, 2009. The median follow-up was 37 months, (range from 2 to 146 months). At each follow-up visit, we carried out a complete clinical examination of the patient. Serum alphafetoprotein (AFP), abdomen ultrasonography and chest $x$-ray were carried out once every 1-3 monthly in the first year, and once every 3-6 monthly thereafter. When tumor recurrence was suspected, computed tomography and/or magnetic resonance imaging and/or positron emission tomography were done. Whenever possible, salvage treatments were given to patients with recurrence or metastases. The treatments included re-resection, transarterial chemoembolization, radiofrequency ablation, percutaneous ethanol injection and systemic chemotherapy.

\section{Statistical Analysis}

Continuous data were expressed as either mean \pm S.D. or medians (range), where appropriate. Chi-square or 
Fisher's exact test was used to compare the difference of categorical variables. The primary endpoints were overall survival (OS) and cumulative recurrence rates (CRR). OS was defined as the interval from curative surgery to the date of death or the date of last contact if the patient was still alive. Time to tumor recurrence was defined as the interval from surgery to the date when tumor recurrence or metastasis was diagnosed. The survival curves were calculated by the Kaplan-Meier method and compared using the log-rank test. Significant prognostic factors on univariate analysis were entered into a multivariate analysis using the Cox proportional hazards model. A p-value $<0.05$ was considered as significant. Statistical procedures were performed using the SPSS software package (Version 15.0; SPSS Inc., Chicago, IL).

\section{Results}

\section{Demographic and Clinicopathological Data}

The demographic and clinicopathological characteristics of the 298 patients with locally advanced HCC in this study are listed in Table 1 . In 16 patients, TACE was given followed by hepatic resection after shrinkage of the tumor, and in 76 patients postoperative adjuvant TACE was given. At the time this study was censored, tumor recurrence was diagnosed in 271 patients (90.9\%), and 253 patients $(84.9 \%)$ had died. For the 271 patients with recurrence, 249 patients had intrahepatic recurrence, 15 had both intrahepatic and extrahepatic recurrences, and 7 had extrahepatic recurrence. The 3-year/ 5 -year OS and CRR of the total cohort after hepatic resection were $28.2 \% / 16.9 \%$ and $85.7 \% / 90.8 \%$, respectively.

\section{Prognostic Factors for Survival and Recurrence}

Among the 24 clinicopathological factors analyzed by univariate log-rank analysis, only albumin (ALB) level $(P=0.004)$, cirrhosis status $(P=0.028)$ and major vascular invasion $(P<0.001)$ were identified as poor prognostic factors for OS (Table 2). The significant prognostic factors found on univariate analysis were further tested in the multivariate Cox model. Major vascular invasion was found to be the most significant factor $(\mathrm{HR}=3.291,95 \% \mathrm{CI} 2.362-4.584, P<0.001)$, followed by cirrhosis status $(\mathrm{HR}=1.400,95 \%$ CI 1.010 1.941, $P=0.044$ ). (Table 3)

When the same factors in Tables 2 were analyzed for their prognostic influence on cumulative recurrence rate, only ALB level $(P=0.002)$ and major vascular invasion $(P<0.001)$ were significant factors in the univariate analysis. The 1-year/3-year CRRs of 61 patients with major vascular invasion were $85.2 \% / 100.0 \%$, whereas the corresponding CRRs of 237 patients without major vascular invasion were $54.7 \% / 80.2 \%$, respectively. In multivariate analysis, major vascular invasion was the only significant predictive factor of CRR $(\mathrm{HR}=2.242,95 \% \mathrm{CI}=1.811-3.358, P<0.001)$. (Table 3)

\section{The Impact of Major Vascular Invasion in Stage pT3/ 4NOMO HCC}

To further verify the grave impact of major vascular invasion on overall survival and recurrence risk in stage pT3/4N0M0 HCC at presentation, we selected patients in whom the four pathologic features were present singularly, and classified them into four subgroups: "Major vascular invasion $(\mathrm{n}=21)$ " as Gp1, "Multiple tumors more than $5 \mathrm{~cm}(\mathrm{n}=108)$ " as Gp2, "Invasion of adjacent organs $(n=32)$ " as Gp3, and "Perforation of visceral peritoneum $(n=57)$ " as Gp4. Comparisons of clinicopathological data of the four subgroups of patients with pT3/4N0M0 HCC are depicted in Table 1. The four groups were not significantly different in liver function parameters and tumor histological features, except that there was a significantly higher proportion of microvascular invasion in tumors with major vascular invasion than the other three groups. Serum AFP levels were also significantly higher in patients with major vascular invasion compared with the other three groups. Intraoperative blood loss, the proportion of patients requiring blood transfusion, and the proportion of patients receiving preoperative and postoperative TACE were all similar.

As shown in Figure 1A, the OS of Gp1 (median 5.8 months) was significantly worse than Gp2 (median 21.7 months, $P<0.001$ ), Gp3 (median 17.3 months, $P<$ 0.001 ) and Gp4 (median 19.5 months, $P=0.001$ ). Similarly, the 3-year CRR of Gp1 (100\%) was significantly higher than Gp2 (79.9\%, $P<0.001)$, Gp3 $(85.5 \%, P=$ $0.006)$ and Gp4 (84.2\%, $P=0.001)$ (Figure 1B). There were no significant differences in OS or in CRR between the latter three subgroups $(P>0.05)$.

To evaluate whether concomitant major vascular invasion influenced survival of patients with other pathologic features, we identified the following three subgroups: "patients with multiple tumors more than 5 $\mathrm{cm}$ and major vascular invasion" as Gp5 ( $\mathrm{n}=17)$, "patients with invasion of adjacent organs and major vascular invasion" as Gp6 $(\mathrm{n}=10)$, and "patients with perforation of visceral peritoneum and major vascular invasion" as Gp7 ( $\mathrm{n}=13)$. Median survivals of Gp5, Gp6 and Gp7 were 7.6 months, 5.7 months and 4.3 months, respectively, while the 3-year CRR of which was all 100\%. The OS and CRR of Gp5, Gp6 and Gp7 were compared with Gp1 (major vascular invasion, $\mathrm{n}=$ 21 ). Results showed that there were no significant differences of OS (Figure 2A) or CRR (Figure 2B) among these four subgroups $(P>0.05)$. 
Table 1 Clinicopathological characteristics of the whole cohort and four subgroups of patients with pT3/4NOMO HCC *

\begin{tabular}{|c|c|c|c|c|c|}
\hline Characteristics & $\begin{array}{l}\text { Whole cohort } \\
(n=298)\end{array}$ & $\begin{array}{l}\text { Major vascular } \\
\text { invasion }(n=21)\end{array}$ & $\begin{array}{l}\text { Multiple tumors more than } \\
5 \mathrm{~cm}(\mathrm{n}=108)\end{array}$ & $\begin{array}{l}\text { Invasion of adjacent } \\
\text { organs }(n=32)\end{array}$ & $\begin{array}{l}\text { Perforation of visceral } \\
\text { peritoneum }(n=57)\end{array}$ \\
\hline $\begin{array}{l}\text { Gender, Male: } \\
\text { Female }\end{array}$ & $276: 22$ & $20: 1$ & $100: 8$ & $30: 2$ & $51: 6$ \\
\hline Age (years) & $48.0 \pm 10.7$ & $48.4 \pm 12.5$ & $46.1 \pm 10.6$ & $49.0 \pm 8.2$ & $45.6 \pm 10.1$ \\
\hline HBsAg positive & 257 (86.2\%) & $17(81.0 \%)$ & $85(78.7 \%)$ & 26(81.3\%) & $51(89.5 \%)$ \\
\hline HCVAb positive & $18(6.0 \%)$ & $1(4.8 \%)$ & $3(2.8 \%)$ & $2(6.3 \%)$ & $3(5.3 \%)$ \\
\hline ALB $(g / L)$ & $42.7 \pm 5.4$ & $40.0 \pm 4.8$ & $43.1 \pm 5.1$ & $39.7 \pm 5.7$ & $43.4 \pm 5.2$ \\
\hline TBIL $(\mu \mathrm{mol} / \mathrm{L})$ & $17.0 \pm 9.5$ & $18.0 \pm 10.9$ & $16.4 \pm 9.6$ & $17.6 \pm 10.1$ & $16.6 \pm 5.9$ \\
\hline PT (s) & $13.6 \pm 1.8$ & $13.9 \pm 2.5$ & $13.6 \pm 1.9$ & $14.2 \pm 2.1$ & $13.0 \pm 1.9$ \\
\hline ICGR15 (\%) & $11.1 \pm 6.4$ & $12.9 \pm 6.8$ & $10.0 \pm 5.6$ & $10.3 \pm 4.3$ & $8.2 \pm 2.8$ \\
\hline $\begin{array}{l}\operatorname{AFP}(\mu \mathrm{g} / \mathrm{L}) \\
\text { median (range) }^{+}\end{array}$ & $488(1-332318)$ & 2839(76-46135) & $487(1-332318)$ & $151.5(2-32318)$ & $817(2-266360)$ \\
\hline Child-Pugh A & $260(87.6 \%)$ & $19(90.5 \%)$ & $97(89.8 \%)$ & $27(84.4 \%)$ & $48(84.2 \%)$ \\
\hline $\begin{array}{l}\text { MELD score } \\
\text { median (range) }\end{array}$ & $7(6-14)$ & $7(6-9)$ & $7(6-14)$ & $7(6-11)$ & $7(6-10)$ \\
\hline Cirrhosis & 241 (80.9\%) & 17(80.9\%) & $89(82.4 \%)$ & $26(81.3 \%)$ & 45(78.9\%) \\
\hline Tumor size $(\mathrm{cm})$ & $9.7 \pm 3.8$ & $8.6 \pm 2.70$ & $9.1 \pm 3.0$ & $10.9 \pm 3.5$ & $8.8 \pm 2.8$ \\
\hline $\begin{array}{l}\text { Tumor } \\
\text { encapsulation }\end{array}$ & 87 (29.2\%) & $5(23.8 \%)$ & $36(33.3 \%)$ & $8(25.0 \%)$ & $14(24.6 \%)$ \\
\hline $\begin{array}{l}\text { Microvascular } \\
\text { invasion }\end{array}$ & $187(62.8 \%)$ & $21(100 \%)$ & $51(47.2 \%)$ & $20(62.5 \%)$ & $32(56.1 \%)$ \\
\hline $\begin{array}{l}\text { Resection margin } \\
>0 \mathrm{~mm}\end{array}$ & 110 (36.9\%) & $6(28.6 \%)$ & $39(36.1 \%)$ & $12(37.5 \%)$ & 19(33.3\%) \\
\hline $\begin{array}{l}\text { Major hepatic } \\
\text { resection }\end{array}$ & 217 (72.8\%) & $16(76.2 \%)$ & $81(75 \%)$ & $21(65.6 \%)$ & $38(66.7 \%)$ \\
\hline Blood loss, liters & $0.8 \pm 0.5$ & $0.9 \pm 0.4$ & $0.8 \pm 0.6$ & $0.7 \pm 0.4$ & $0.8 \pm 0.7$ \\
\hline Blood transfusion & 157 (52.7\%) & 14(66.7\%) & $57(53.3 \%)$ & $22(68.7 \%)$ & $36(63.2 \%)$ \\
\hline Previous TACE & $16(5.4 \%)$ & $1(3.1 \%)$ & $5(4.6 \%)$ & $2(6.3 \%)$ & $2(3.5 \%)$ \\
\hline $\begin{array}{l}\text { Postoperative } \\
\text { adjuvant TACE }\end{array}$ & 76 (25.5\%) & $6(28.6 \%)$ & $32(33.3 \%)$ & $7(21.9 \%)$ & $9(15.8 \%)$ \\
\hline
\end{tabular}

Unless otherwise stated, continuous data are expressed as mean $\pm \mathrm{SD}$; other figures indicate number of patients.

HBsAg, hepatitis B surface antigen; HCVAb, hepatitis C virus antibody; ALB, albumin; TBIL, total bilirubin; PT, prothrombin time; ICGR15, indocyanine green retention rate at 15 minutes; AFP, $\alpha$-fetoprotein; MELD, model for end-stage liver disease; TACE, transarterial chemoembolization.

* The four subgroups were selected patients in whom the four pathologic features present singularly.

+ Serum AFP levels of patients with major vascular invasion were significantly higher than those of the other three subgroups $(P<0.05)$.

* The proportion of patients with microvascular invasion was significantly higher in patients with major vascular invasion than in the other three subgroups $(P<$ 0.05).

There were no significant differences between any groups in any other parameters.

\section{Recurrence Type in Four Groups of Locally Advanced HCC} Since recurrence is the main cause of death after curative partial hepatectomy for HCC, we evaluated the difference in recurrence type for the four categories of locally advanced HCC (Gp1-4). We classified tumor recurrence into early or late with 12 months as the cutoff point, $[13,14]$ and the number of recurrent nodules into single or multiple recurrence. As shown in Table 4, early recurrence occurred in $90.5 \%$ of Gp1, which was significant higher than Gp2, Gp3 and Gp4 $(P=0.006$, 0.041 and 0.024 , respectively). Multiple recurrence was observed in $85.7 \%$ of Gp1, which was also significantly higher than Gp3 and Gp4 $(P=0.039$ and 0.036, respectively).

\section{Discussion}

To provide a better prognostic prediction for cancer patients, the AJCC/UICC TNM staging system has been updated periodically based on new evidence from clinical studies [15]. In 2002, the TNM staging system for HCC was revised and it put more emphasis on vascular invasion. However, patients with major vascular invasion are still classified as pT3 after this revision. Many studies have shown $\mathrm{HCC}$ with major vascular invasion had extremely poor outcomes, [6,7] but HCC with invasion of adjacent organs or perforation of visceral peritoneum were not definitely associated with such a poor prognosis $[10,11]$. Thus, there is a need to reassess the accuracy of the current TNM classification for pT3-4 tumors. 
Table 2 Univariate analysis of prognostic factors by logrank test

\begin{tabular}{|c|c|c|c|c|c|}
\hline Variable & Cases & $\begin{array}{c}1 y-O S \\
(\%)\end{array}$ & $\begin{array}{c}3 y-O S \\
(\%)\end{array}$ & $\begin{array}{c}5 y-O S \\
(\%)\end{array}$ & $P$ \\
\hline Gender & & & & & 0.913 \\
\hline Female & 22 & 45.5 & 31.8 & 18.2 & \\
\hline Male & 276 & 59.1 & 25.9 & 15.9 & \\
\hline Age (years) & & & & & 0.079 \\
\hline$\leq 48$ & 146 & 54.7 & 22.9 & 13.7 & \\
\hline$>48$ & 152 & 60.5 & 29.6 & 18.3 & \\
\hline $\mathrm{HBsAg}$ & & & & & 0.269 \\
\hline Negative & 41 & 58.7 & 37.6 & 18.8 & \\
\hline Positive & 257 & 56.5 & 23.2 & 14.9 & \\
\hline HCVAb & & & & & 0.380 \\
\hline Negative & 280 & 55.2 & 27.3 & 18.2 & \\
\hline Positive & 18 & 47.5 & 22.0 & 12.9 & \\
\hline ALB (g/L) & & & & & 0.004 \\
\hline$\leq 35$ & 37 & 42.3 & 7.7 & 0.0 & \\
\hline$>35$ & 261 & 59.6 & 27.7 & 17.3 & \\
\hline TBIL ( $\mu \mathrm{mol} / \mathrm{L})$ & & & & & 0.879 \\
\hline$\leq 20$ & 204 & 62.8 & 29.3 & 16.0 & \\
\hline$>20$ & 94 & 58.0 & 28.0 & 14.3 & \\
\hline PT (s) & & & & & 0.185 \\
\hline$\leq 13.5$ & 148 & 62.0 & 32.9 & 22.3 & \\
\hline$>13.5$ & 150 & 57.0 & 24.6 & 14.4 & \\
\hline ICGR15 (\%) & & & & & 0.423 \\
\hline$\leq 10$ & 155 & 52.2 & 26.7 & 17.8 & \\
\hline$>10$ & 143 & 61.7 & 28.2 & 19.4 & \\
\hline AFP $(\mu \mathrm{g} / \mathrm{L})$ & & & & & 0.112 \\
\hline$\leq 25$ & 48 & 63.2 & 34.3 & 20.5 & \\
\hline$>25$ & 250 & 56.0 & 25.8 & 16.0 & \\
\hline Child-Pugh & & & & & 0.275 \\
\hline A & 260 & 59.4 & 27.4 & 16.5 & \\
\hline B & 38 & 50.0 & 18.8 & 12.5 & \\
\hline MELD & & & & & 0.243 \\
\hline$\leq 7$ & 169 & 58.0 & 24.7 & 13.9 & \\
\hline$>7$ & 129 & 57.2 & 32.6 & 20.7 & \\
\hline Cirrhosis & & & & & 0.028 \\
\hline No & 57 & 61.0 & 39.5 & 26.6 & \\
\hline Yes & 241 & 57.8 & 23.5 & 13.8 & \\
\hline Tumor size(cm) & & & & & 0.278 \\
\hline$\leq 5$ & 35 & 66.0 & 31.0 & 21.0 & \\
\hline$>5$ & 263 & 56.0 & 23.5 & 14.5 & \\
\hline Variable & Cases & $\begin{array}{c}1 y-O S \\
(\%)\end{array}$ & $\begin{array}{c}3 y-O S \\
(\%)\end{array}$ & $\begin{array}{c}5 y-O S \\
(\%)\end{array}$ & $P$ \\
\hline Tumor number & & & & & 0.101 \\
\hline Solitary & 108 & 59.7 & 33.3 & 23.3 & \\
\hline Multiple & 190 & 57.8 & 23.1 & 12.5 & \\
\hline Tumor location & & & & & 0.126 \\
\hline Unilobar & 255 & 52.7 & 27.2 & 17.3 & \\
\hline Bilobar & 43 & 45.2 & 21.4 & 10.0 & \\
\hline Tumor encapsulation & & & & & 0.093 \\
\hline Yes & 87 & 54.1 & 26.1 & 18.1 & \\
\hline No & 211 & 44.1 & 17.0 & 12.0 & \\
\hline
\end{tabular}

Table 2: Univariate analysis of prognostic factors by logrank test (Continued)

\begin{tabular}{|c|c|c|c|c|c|}
\hline Microvascular invasion & & & & & 0.117 \\
\hline No & 111 & 56.5 & 24.0 & 16.7 & \\
\hline Yes & 187 & 48.1 & 19.4 & 11.0 & \\
\hline Major vascular invasion & & & & & $<0.001$ \\
\hline No & 237 & 65.2 & 32.2 & 19.6 & \\
\hline Yes & 61 & 29.7 & 0.0 & 0.0 & \\
\hline $\begin{array}{l}\text { Invasion of adjacent } \\
\text { organs }\end{array}$ & & & & & 0.197 \\
\hline No & 219 & 59.9 & 27.7 & 16.0 & \\
\hline Yes & 69 & 56.3 & 17.0 & 12.4 & \\
\hline $\begin{array}{l}\text { Perforation of visceral } \\
\text { peritoneum }\end{array}$ & & & & & 0.295 \\
\hline No & 220 & 60.1 & 26.9 & 18.4 & \\
\hline Yes & 78 & 53.8 & 21.0 & 13.6 & \\
\hline Resection margin(mm) & & & & & 0.201 \\
\hline 0 & 188 & 49.3 & 20.8 & 12.7 & \\
\hline$>0$ & 110 & 58.4 & 26.1 & 17.9 & \\
\hline Resection extent & & & & & 0.062 \\
\hline Major & 217 & 54.7 & 23.5 & 15.2 & \\
\hline Minor & 81 & 67.9 & 28.0 & 18.9 & \\
\hline Blood loss(L) & & & & & 0.140 \\
\hline$\leq 0.8$ & 163 & 62.8 & 30.5 & 21.5 & \\
\hline$>0.8$ & 135 & 52.9 & 21.2 & 12.9 & \\
\hline Blood transfusion & & & & & 0.488 \\
\hline No & 142 & 59.0 & 26.3 & 17.6 & \\
\hline Yes & 157 & 57.9 & 26.6 & 14.4 & \\
\hline Previous TACE & & & & & 0.724 \\
\hline No & 282 & 57.3 & 27.1 & 16.4 & \\
\hline Yes & 16 & 48.4 & 21.3 & 13.2 & \\
\hline $\begin{array}{l}\text { Postoperative adjuvant } \\
\text { TACE }\end{array}$ & & & & & 0.923 \\
\hline No & 222 & 61.7 & 28.6 & 15.5 & \\
\hline Yes & 76 & 53.2 & 23.0 & 15.2 & \\
\hline
\end{tabular}

The issue whether HCC with major vascular invasion is correctly classified was first raised by Poon et al. In their series, patients with major vascular invasion had significantly worse long-term survival compared with the other three categories of stage IVA HCC in the previous version of the TNM classification [7]. In a multicenter study which was the basis of the current TNM staging system, Vauthey et al also showed that the survival of patients with multiple bilobar tumors or invasion of adjacent organs was better than patients with tumors with major vascular invasion [6]. However, a major limitation of their study is that the number of patients with invasion of adjacent organs was relatively small $(n=11$, or $2 \%$ of the total cohort). Thus, AJCC/UICC decided not to change the definition of pT4 for the 2002 version of the TNM classification. In our present study, major vascular invasion showed the strongest impact on prognosis both in univariate and multivariate analyses. 
Table 3 Univariate and multivariate Cox regression analyses for overall survival and cumulative recurrence rate

\begin{tabular}{|c|c|c|c|c|c|c|c|c|}
\hline \multirow[b]{3}{*}{ Variable } & \multicolumn{4}{|c|}{ Univariate analysis } & \multicolumn{4}{|c|}{ Multivariate analysis } \\
\hline & \multicolumn{2}{|c|}{ OS } & \multicolumn{2}{|c|}{ CRR } & \multicolumn{2}{|c|}{ OS } & \multicolumn{2}{|c|}{ CRR } \\
\hline & HR & $P$ & HR & $P$ & $\mathrm{HR}$ & $P$ & HR & $P$ \\
\hline Major vascular invasion* & 3.500 & $<0.001$ & 2.436 & $<0.001$ & 3.291 & $<0.001$ & 2.242 & $<0.001$ \\
\hline ALB level $^{\dagger}$ & 0.601 & 0.004 & 0.541 & 0.002 & 0.693 & 0.094 & 0.689 & 0.066 \\
\hline Cirrhosis status $^{\ddagger}$ & 1.319 & 0.028 & 1.223 & 0.190 & 1.400 & 0.044 & - & - \\
\hline
\end{tabular}

OS, overall survival; $C R R$, cumulative recurrence rate; $\mathrm{HR}$, hazard ratio.

* Major vascular invasion vs. No major vascular invasion.

${ }^{+}$ALB $>35 \mathrm{~g} / \mathrm{L}$ vs. $<35 \mathrm{~g} / \mathrm{L}$.

* Cirrhosis vs. No cirrhosis.

Furthermore, applying the criteria used in the 2002 TNM classification, patients with HCC with major vascular invasion (pT3) in our study had worse survival and more recurrence than HCC with invasion of adjacent organs or perforation of visceral peritoneum (pT4) or multiple tumors more than $5 \mathrm{~cm}$ (pT3). Moreover, for patients who had major vascular invasion combined with any of the other three locally advanced pathologic features, the prognosis was similar to patients with HCC with major vascular invasion only. Our results indicated that once major vascular invasion occurred, prognosis became so poor that it was regardless of the presence or absence of any other tumor characteristics. Our data showed there is a need to redefine the $\mathrm{T}$ classification and to put more emphasize on major vascular invasion because of its overwhelmingly adverse prognostic influence.
It has also been widely accepted that major vascular invasion indicates advanced $\mathrm{HCC}$ with a high risk of recurrence, which is the main cause of death for HCC patients after surgical resection [14,16,17]. In the present study, tumor recurrence was observed in all patients with HCC with major vascular invasion. The incidences of early and/or multiple recurrence for HCC with major vascular invasion was the highest in the four categories of locally advanced HCC, while there were no significant differences in the recurrence types among the remaining three groups of patients. Similar results have also been reported by Portolani et al [16]. In their series, major vascular invasion correlated well with early and diffuse recurrence which was rarely treatable, and thus an unsatisfactory long-term survival. As multiple tumors can be due to multicentric occurrence, they are likely to be associated with a better prognosis $[18,19]$. The study by

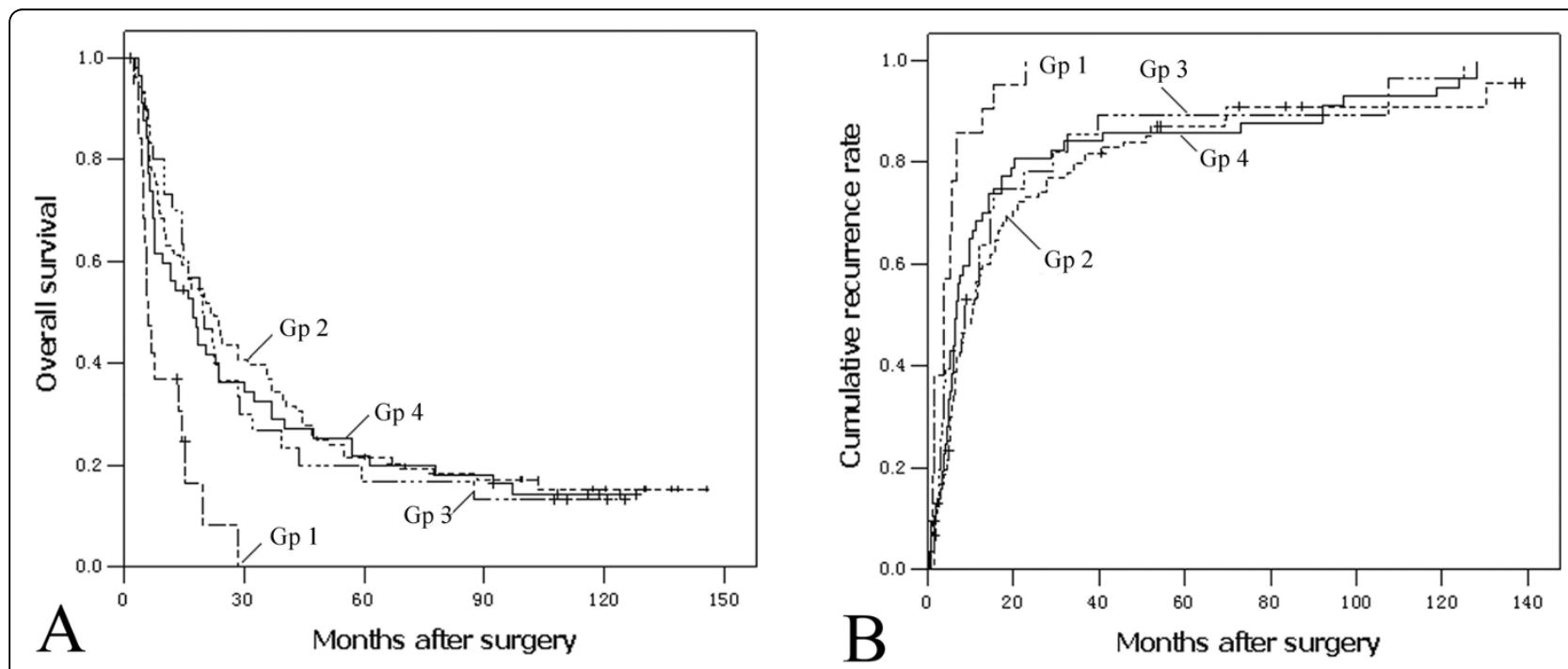

Figure 1 Kaplan-Meier curves of overall survival and cumulative recurrence rates of four categories of locally advanced HCC patients Gp1, major vascular invasion ( $n=21)$; Gp2, multiple tumors more than $5 \mathrm{~cm}(\mathrm{n}=108)$; Gp3, invasion of adjacent organs ( $\mathrm{n}=32$ ); Gp4, perforation of visceral peritoneum ( $\mathrm{n}=57$ ). (A) Overall survival; Gp1 vs. Gp2, $P<0.001$; Gp1 vs.Gp3, $P=0.001$; Gp1 vs. Gp4, $P<0.001$; Gp2 vs. Gp3, $P=0.892 ; G p 2$ vs. Gp4, $P=0.693 ; \mathrm{Gp3}$ vs. Gp4, $P=0.615$. (B) Cumulative recurrence rate; Gp1 vs. Gp2, $P=0.006 ; \mathrm{Gp} 1$ vs.Gp3, $P=0.001$; Gp1 vs. Gp4, $P<0.001 ; G p 2$ vs. Gp3, $P=0.991 ; G p 2$ vs. Gp4, $P=0.299 ; G p 3$ vs. Gp4, $P=0.169$. 

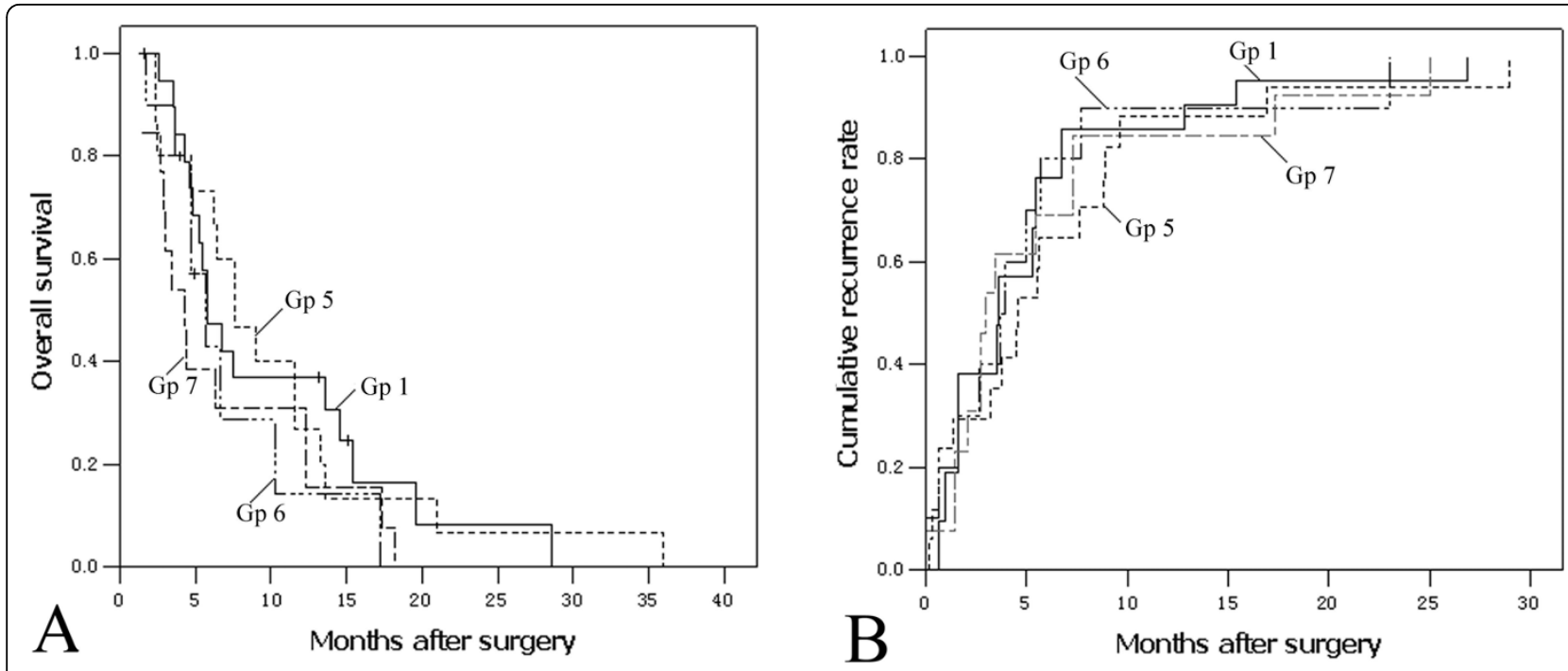

Figure 2 Kaplan-Meier curves of overall survival and cumulative recurrence rates to compare vascular invasion with or without any of the other pathologic features of locally advanced HCC patients. Gp1, major vascular invasion ( $n=21)$; Gp5, multiple tumors more than 5 $\mathrm{cm}$ and major vascular invasion ( $\mathrm{n}=17) ; \mathrm{Gp6}$, invasion of adjacent organs and major vascular invasion $(\mathrm{n}=10)$; Gp7, perforation of visceral peritoneum and major vascular invasion $(n=13)$. (A) Overall survival; Gp1 vs. Gp5, $P=0.392 ; G p 1$ vs.Gp6, $P=0.121 ; G p 1$ vs. Gp7, $P=0.901 ; G p 5$ vs. Gp6, $P=0.854 ;$ Gp5 vs. Gp7, $P=0.287$; Gp6 vs. Gp7, $P=0.250$. (B) Cumulative recurrence rate; $G p 1$ vs. Gp5, $P=0.914 ; G p 1$ vs.Gp6, $P=0.909$; Gp1 vs. Gp7, $P=0.455 ; G p 5$ vs. Gp6, $P=0.807 ; G p 5$ vs. Gp7, $P=0.511 ; G p 6$ vs. Gp7, $P=0.651$.

Poon et al. showed early recurrence within one year after resection of HCC was more likely to be due to metastasis than multicentric occurrence and was associated with a worse prognosis when compared with late recurrence [20]. Our results supported that patients with HCC with major vascular invasion had a significantly poorer prognosis than those with multiple tumors more than $5 \mathrm{~cm}$, those with invasion of adjacent organs, or those with perforation of visceral peritoneum.

The prognosis of $\mathrm{HCC}$ is extremely poor in patients with advanced disease [21]. For hepatic resection, the presence of distant metastasis is generally considered a contraindication [22]. In contrast, in view of the lack of other effective treatment options, surgical resection especially in eastern countries, is still advocated as the treatment of choice for patients with locally advanced HCC which is classified as pT3-4NOM0 [22-24]. Ishizawa et al. demonstrated that partial hepatectomy provided survival benefits for patients with multiple tumors with Child-Pugh class A cirrhosis [25]. For locally advanced HCC, studies have also shown that survival following hepatic resection compared favorably with those treated non-surgically $[10,11,26,27]$. To improve future survival rates, innovative multidisciplinary approaches will also be needed. With recent advances in adjuvant therapy such as immunotherapy and molecular targeted therapy, whether these new modalities can improve the prognosis of locally advanced HCC treated with curative resection need to be clarified [28,29].

For patients with major vascular invasion, the prognosis is particularly grave. Nonsurgical treatment with systemic chemotherapy, intra-arterial chemotherapy, or radiofrequency ablation for these patients results in dismal 1 -year survival rates, ranging from $7 \%$ to $18 \%$ [30-32]. Patients with HCC and major vascular invasion do not present technical contraindications to surgery. However, results after hepatic resection for HCC with major vascular invasion have been disappointing $[22,33,34]$. In the current study, the median OS was only 5.8 months after hepatic resection. Recently, the

Table 4 Recurrence types in four groups of locally advanced HCC

\begin{tabular}{|c|c|c|c|c|c|c|c|c|}
\hline \multirow[b]{2}{*}{ Group } & \multirow[b]{2}{*}{ Variables } & \multirow[b]{2}{*}{ Cases } & \multicolumn{3}{|c|}{ Recurrence time* } & \multicolumn{3}{|c|}{ No. of recurrence } \\
\hline & & & Early(\%) & Late(\%) & $P$ & Single(\%) & Multiple(\%) & $P$ \\
\hline Gp1 & Major vascular invasion only & 21 & $19(90.5)$ & $2(9.5)$ & & $3(14.3)$ & $18(85.7)$ & \\
\hline Gp2 & Multiple tumors more than $5 \mathrm{~cm}$ only & 108 & $54(58.7)$ & $38(41.3)$ & 0.006 & $32(34.8)$ & $60(65.2)$ & 0.067 \\
\hline Gp3 & Invasion of adjacent organs only & 32 & $19(65.5)$ & $10(34.5)$ & 0.041 & $12(41.4)$ & $17(58.6)$ & 0.039 \\
\hline Gp4 & Perforation of visceral peritoneum only & 57 & $34(64.2)$ & $19(35.8)$ & 0.024 & 21 (39.6) & $32(60.4)$ & 0.036 \\
\hline
\end{tabular}

* Early recurrence, recurrence $\leq 12$ months; late recurrence, recurrence $>12$ months. 
efficacy of Sorafenib in patients with advanced HCC has been evaluated in a randomized, double-blind, multicentre, phase III trials: the SHARP (Sorafenib Hepatocellular Carcinoma Assessment Randomized Protocol) trial [35]. However, the placebo group of the SHARP study with similar baseline characteristics as in this study had a median survival of 7.9 months. It seems that these patients may not benefit from resection or even suffer detrimental effects. Since there are no head-to-head studies comparing resection and nonsurgical treatment or sorafenib in this category of patients, future studies will need to investigate more thoroughly which modality should be used as first line treatment.

There are several limitations of our study. Our study is retrospective and it is based on a single-institutional experience. The sample size of some of the subgroups is relatively small. A larger scale, multi-center study is needed to confirm our results.

\section{Conclusion}

In conclusion, our study suggested that the current 2002 TNM staging system failed to stratify patients with different categories of locally advanced HCC according to the outcomes after hepatic resection. The current pT3 subgroup of major vascular invasion exhibited poor surgical outcomes when compared with the other pT3 subgroups with multiple tumors more than $5 \mathrm{~cm}$, and the pT4 group with invasion of adjacent organs or perforation of visceral peritoneum. These data, in addition to the published data, challenge the value of the current 2002 TNM staging classification in locally advanced HCC.

\section{Acknowledgements}

This work was supported by grants from National Natural Science Foundation of China (30872489 and 30972916). We are grateful to Professor Qing Liu (Dept. of GCP, Sun Yat-sen University Cancer Center, Guangzhou, China) for supporting the statistical analysis.

\section{Author details \\ ${ }^{1}$ State Key Laboratory of Oncology in South China, Guangzhou, China. 2Department of Hepatobiliary Oncology, Sun Yat-sen University Cancer Center, Guangzhou, China. ${ }^{3}$ Department of Surgery, The Third Affiliated Hospital, Sun Yat-sen University, Guangzhou, China. ${ }^{4}$ Department of Radiation Oncology, Sun Yat-sen University Cancer Center, Guangzhou, China. ${ }^{5}$ Faculty of Medicine, The Chinese University of Hong Kong, Prince of Wales Hospital, Shatin, New Territories, Hong Kong SAR, China.}

\section{Authors' contributions}

$B K L, Y F Y, J Q L$, and GHL have made substantial contributions to conception and design of the study. BKL, GHC, and YQZ carried out acquisition of data. $B K L, G H C$, and $L R H$ carried out analysis and interpretation of data. BKL, YFY, $\mathrm{LRH}$ and $\mathrm{WYL}$ have been involved in drafting the manuscript. All authors read and approved the final manuscript.

\section{Competing interests}

The authors declare that they have no competing interests.
References

1. Jemal A, Siegel R, Ward E, Hao Y, Xu J, Murray T, Thun MJ: Cancer statistics, 2008. CA Cancer J Clin 2008, 58:71-96.

2. El-Serag HB, Rudolph KL: Hepatocellular carcinoma: epidemiology and molecular carcinogenesis. Gastroenterology 2007, 132:2557-2576.

3. Henderson J, Sherman M, Tavill A, Abecassis M, Chejfec G, Gramlich T: AHPBA/AJCC consensus conference on staging of hepatocellular carcinoma: consensus statement. HPB (Oxford) 2003, 5:243-250.

4. Minagawa M, Ikai I, Matsuyama Y, Yamaoka Y, Makuuchi M: Staging of hepatocellular carcinoma: assessment of the Japanese TNM and AJCC/ UICC TNM systems in a cohort of 13,772 patients in Japan. Ann Surg 2007, 245:909-922.

5. Kee KM, Wang JH, Lee CM, Chen $\mathrm{CL}$, Changchien $\mathrm{CS}$, Hu TH, Cheng YF, Hsu HC, Wang CC, Chen TY, et al: Validation of clinical AJCC/UICC TNM staging system for hepatocellular carcinoma: analysis of 5,613 cases from a medical center in southern Taiwan. Int J Cancer 2007, 120:2650-2655.

6. Vauthey JN, Lauwers GY, Esnaola NF, Do KA, Belghiti J, Mirza N, Curley SA, Ellis LM, Regimbeau JM, Rashid A, et al: Simplified staging for hepatocellular carcinoma. J Clin Oncol 2002, 20:1527-1536.

7. Poon RT, Fan ST, Ng IO, Wong J: Prognosis after hepatic resection for stage IVA hepatocellular carcinoma: a need for reclassification. Ann Surg 2003, 237:376-383

8. Greene FL, Page DL, Fleming ID, eds: AJCC cancer staging manual. Chicago: Springer, 6 2002, 131-44.

9. Sobin LH, Wittekind C, eds: UICC TNM Classification of Malignant Tumors. New York: John Wiley \& Sons, 6 2002, 81-6.

10. Tung WY, Chau GY, Loong CC, Wu JC, Tsay SH, King KL, Huang SM, Chiu JH, Wu CW, Lui WY: Surgical resection of primary hepatocellular carcinoma extending to adjacent organ(s). Eur J Surg Oncol 1996, 22:516-520.

11. Lau WY, Leung KL, Leung TW, Liew CT, Chan M, Li AK: Resection of hepatocellular carcinoma with diaphragmatic invasion. Br J Surg 1995, 82:264-266.

12. Malinchoc M, Kamath PS, Gordon FD, Peine CJ, Rank J, ter Borg PC: A model to predict poor survival in patients undergoing transjugular intrahepatic portosystemic shunts. Hepatology 2000, 31:864-871.

13. Poon RT, Fan ST, Ng IO, Lo CM, Liu CL, Wong J: Different risk factors and prognosis for early and late intrahepatic recurrence after resection of hepatocellular carcinoma. Cancer 2000, 89:500-507.

14. Kawano Y, Sasaki A, Kai S, Endo Y, Iwaki K, Uchida H, Shibata K, Ohta M, Kitano S: Prognosis of patients with intrahepatic recurrence after hepatic resection for hepatocellular carcinoma: a retrospective study. Eur J Surg Oncol 2009, 35:174-179.

15. Gospodarowicz MK, Miller D, Groome PA, Greene FL, Logan PA, Sobin LH: The process for continuous improvement of the TNM classification. Cancer 2004, 100:1-5

16. Portolani N, Coniglio A, Ghidoni S, Giovanelli M, Benetti A, Tiberio GA, Giulini SM: Early and late recurrence after liver resection for hepatocellular carcinoma: prognostic and therapeutic implications. Ann Surg 2006, 243:229-235.

17. Sonoyama T, Ochiai T, Hironaka T, Yamagishi H: Predictors of postoperative diffuse intrahepatic recurrence of hepatocellular carcinoma. Hepatogastroenterology 2003, 50:1078-1084

18. Wilkens L, Bredt M, Flemming P, Klempnauer J, Heinrich Kreipe H: Differentiation of multicentric origin from intra-organ metastatic spread of hepatocellular carcinomas by comparative genomic hybridization. J Pathol 2000, 192:43-51.

19. Li Q, Wang J, Juzi JT, Sun Y, Zheng H, Cui Y, Li H, Hao X: Clonality analysis for multicentric origin and intrahepatic metastasis in recurrent and primary hepatocellular carcinoma. J Gastrointest Surg 2008, 12:1540-1547.

20. Poon RT, Fan ST, Lo CM, Liu CL, Wong J: Intrahepatic recurrence after curative resection of hepatocellular carcinoma: long-term results of treatment and prognostic factors. Ann Surg 1999, 229:216-222.

21. Usatoff $\mathrm{V}$, Isla $A M$, Habib NA: Liver resection in advanced hepatocellular carcinoma. Hepatogastroenterology 2001, 48:46-50.

22. Ikai I, Yamaoka Y, Yamamoto Y, Ozaki N, Sakai Y, Satoh S, Shinkura N, Yamamoto M: Surgical intervention for patients with stage IV-A hepatocellular carcinoma without lymph node metastasis: proposal as a standard therapy. Ann Surg 1998, 227:433-439. 
23. Shimada M, Takenaka K, Kawahara N, Kajiyama K, Yamamoto K, Shirabe K, Nishizaki T, Yanaga K, Sugimachi K: Surgical treatment strategy for patients with stage IV hepatocellular carcinoma. Surgery 1996 119:517-522.

24. Chirica M, Scatton O, Massault PP, Aloia T, Randone B, Dousset B, Legmann P, Soubrane O: Treatment of stage IVA hepatocellular carcinoma: should we reappraise the role of surgery? Arch Surg 2008, 143:538-543, discussion 543.

25. Ishizawa T, Hasegawa K, Aoki T, Takahashi M, Inoue Y, Sano K, Imamura H, Sugawara Y, Kokudo N, Makuuchi M: Neither multiple tumors nor portal hypertension are surgical contraindications for hepatocellular carcinoma. Gastroenterology 2008, 134:1908-1916.

26. Hasegawa K, Kokudo N: Surgical treatment of hepatocellular carcinoma. Surg Today 2009, 39:833-843.

27. Ng KK, Vauthey JN, Pawlik TM, Lauwers GY, Regimbeau JM, Belghiti J, Ikai I, Yamaoka Y, Curley SA, Nagorney DM, et al: Is hepatic resection for large or multinodular hepatocellular carcinoma justified? Results from a multiinstitutional database. Ann Surg Oncol 2005, 12:364-373.

28. Llovet JM, Bruix J: Novel advancements in the management of hepatocellular carcinoma in 2008. J Hepatol 2008, 48(Suppl 1):S20-37.

29. Llovet JM, Bruix J: Molecular targeted therapies in hepatocellular carcinoma. Hepatology 2008, 48:1312-1327.

30. Okada S, Okazaki N, Nose H, Yoshimori M, Aoki K: Prognostic factors in patients with hepatocellular carcinoma receiving systemic chemotherapy. Hepatology 1992, 16:112-117.

31. Raoul $J L$, Guyader D, Bretagne JF, Duvauferrier R, Bourguet $P$, Bekhechi D, Deugnier YM, Gosselin M: Randomized controlled trial for hepatocellular carcinoma with portal vein thrombosis: intra-arterial iodine-131-iodized oil versus medical support. J Nucl Med 1994, 35:1782-1787.

32. Akashi Y, Koreeda C, Enomoto S, Uchiyama S, Mizuno T, Shiozaki Y, Sameshima Y, Inoue K: Prognosis of unresectable hepatocellular carcinoma: an evaluation based on multivariate analysis of 90 cases. Hepatology 1991, 14:262-268.

33. Ikai I, Yamamoto $Y$, Yamamoto $N$, Terajima H, Hatano E, Shimahara $Y$, Yamaoka Y: Results of hepatic resection for hepatocellular carcinoma invading major portal and/or hepatic veins. Surg Oncol Clin N Am 2003, 12:65-75.

34. Pawlik TM, Poon RT, Abdalla EK, Ikai I, Nagorney DM, Belghiti J, Kianmanesh R, Ng IO, Curley SA, Yamaoka Y, et al: Hepatectomy for hepatocellular carcinoma with major portal or hepatic vein invasion: results of a multicenter study. Surgery 2005, 137:403-410.

35. Llovet JM, Ricci S, Mazzaferro V, Hilgard P, Gane E, Blanc JF, de Oliveira AC, Santoro A, Raoul JL, Forner A, et al: Sorafenib in advanced hepatocellular carcinoma. N Engl J Med 2008, 359:378-390.

\section{Pre-publication history}

The pre-publication history for this paper can be accessed here: http://www.biomedcentral.com/1471-2407/10/535/prepub

doi:10.1186/1471-2407-10-535

Cite this article as: Li et al:: Application of tumor-node-metastasis staging 2002 version in locally advanced hepatocellular carcinoma: is it predictive of surgical outcome?. BMC Cancer 2010 10:535.

\section{Submit your next manuscript to BioMed Central and take full advantage of:}

- Convenient online submission

- Thorough peer review

- No space constraints or color figure charges

- Immediate publication on acceptance

- Inclusion in PubMed, CAS, Scopus and Google Scholar

- Research which is freely available for redistribution

Submit your manuscript at www.biomedcentral.com/submit
Biomed Central 